\title{
Characterization of Single Superphosphate Powders - a study of Milling Effects on Solubilization Kinetics
}

\author{
Fábio Plotegher ${ }^{a, b}$, Caue Ribeiro ${ }^{b *}$ \\ ${ }^{a}$ Departamento de Química, Universidade Federal de São Carlos - UFSCAR, Rodovia Washington Luís, \\ Km 235, CEP 13565-905, São Carlos, SP, Brazil \\ ${ }^{b}$ Embrapa Instrumentação, Rua 15 de Novembro, 1452, CEP 13560-970, São Carlos, SP, Brazil
}

Received: July 10, 2015; Revised: September 28, 2015; Accepted: November 20, 2015

\begin{abstract}
Conventional single superphosphate (SSP) is known as one of the most important and common sources of phosphorus in agriculture. Despite SSP has been widely produced as a fertilizer, a few studies have been done to describe the fundamental aspects of this P-fertilizer, i.e., phase composition, thermal degradation behavior, and solubility kinetics. Therefore, this paper reports on the detailed characterization of SSP powders by correlating their properties with particle size and surface area. Commercial SSP fertilizers were milled under different conditions and the resulting powders were characterized by X-ray diffraction, thermogravimetric analyses, scanning electron microscopy, FT-IR spectroscopy, and solubilization tests. It was observed that short milling times favored the solubilization kinetics, whereas long milling times were deleterious due to agglomeration effects. It was pointed out that agglomeration plays an important role in phosphate availability. These results provided a deeper understanding of SSP powders in microstructural terms, and may be used as a foundation for the development of novel strategies of alternative production of phosphorus fertilizers.
\end{abstract}

Keywords: Superphosphate, Phosphorus, Milling, release, Powder, Solubilization

\section{1 - Introduction}

Phosphorus $(\mathrm{P})$ is an essential element for any living being that exists on Earth. It plays a primary role in the formation of vital biomolecules such as deoxyribonucleic acid (DNA) and nucleotide forms adenosine triphosphate and adenosine diphosphate (ADP and ATP), which store energy and are extremely important for cellular respiration and photosynthesis. Together with nitrogen $(\mathrm{N})$ and potassium (K), P belongs to the class of the three essential macronutrients for development of any kind of plant..$^{1-4}$

In the 19th century, phosphorus fertilization in crops was mainly accomplished with bone meal from slaughtered animals. However, the solubility of this material was not satisfactory enough to ensure the necessary supply of phosphorus to agricultural crops, and as the demand for foods increased, a search for new phosphorus sources became necessary. In 1840, Justus von Leibig found out that the solubilization of bone meal could be assisted by adding sulfuric acid, hence, increased release rates of phosphorus were obtained. Later the same scientist successfully applied the same chemical treatment on phosphate rocks. John Bennet Lawes developed this process at an industrial scale and renamed the product as superphosphate fertilizer, which was the first P-fertilizer commercially produced worldwide. ${ }^{5-7}$ Since its invention, the process for obtaining single superphosphate (SSP) only changed with respect to the phosphorus source. Currently the main source of phosphorus used by the industries to fabricate P-fertilizers is the phosphate rock, which is mainly composed of some kind of apatite, hydroxyapatite $\left(\mathrm{Ca}_{10}\left(\mathrm{PO}_{4}\right)_{6}(\mathrm{OH})_{2}\right)$,

*e-mail: caue.ribeiro@embrapa.br fluorapatite $\left(\mathrm{Ca}_{10}\left(\mathrm{PO}_{4}\right)_{6} \mathrm{~F}_{2}\right)$ or carbonateapatite $\left(\mathrm{Ca}_{10}\left(\mathrm{PO}_{4}\right)_{6} \mathrm{CO}_{3}\right)$. It is estimated that the current fertilizer industry consumes approximately $90 \%$ of all phosphate rock produced worldwide..$^{8-9}$ The chemical reaction for SSP formation can be summarized in the equation below:

$$
\begin{aligned}
& 2 \mathrm{Ca}_{5}\left(\mathrm{PO}_{4}\right)_{3} \mathrm{~F}+7 \mathrm{H}_{2} \mathrm{SO}_{4}+3 \mathrm{H}_{2} \mathrm{O} \rightarrow 7 \mathrm{CaSO}_{4}+ \\
& 3 \mathrm{Ca}\left(\mathrm{H}_{2} \mathrm{PO}_{4}\right)_{2} \cdot \mathrm{H}_{2} \mathrm{O}+2 \mathrm{HF}
\end{aligned}
$$

Essentially, the rock is reacted with dilute sulfuric acid (between 68-75\%) for up to 4 hours. After this time a material of plastic consistency is formed and submitted to a curing process for a few weeks until drying, followed by grinding and granulation..$^{10-13}$ However, despite this apparent simplicity, only a few papers have described the fundamental aspects of SSP, i.e., phase composition, thermal degradation behavior and solubilization kinetics. Particularly, the importance of milling conditions and the resulting particle size was addressed only in empirical studies, where the focus on the agronomical aspects surpassed any evaluation of SSP in terms of microstructural characterization. The textural characterization of SSP is of scientific relevance since it could contribute to the understanding of how the properties of SSP could be tailored in order to obtain more efficient SSP fertilizers as well as to explain why SSP is much more active in soil than the pristine raw materials, despite the similar phase composition.

In this paper we report a detailed characterization of SSP powders milled under different conditions to obtain different particle sizes. Characterizations by thermogravimetry, infrared 
spectroscopy, total surface area measurements, and electron microscopy were correlated with solubilization tests in order to discuss the main factors determining the performance of SSP powders as a P-fertilizer. To the best of our knowledge, this is the first detailed study on relationships between textural property and solubilization kinetics of SSP fertilizers.

\section{2 - Materials and methods}

\subsection{Milling of SSP fertilizer}

The SSP powders were prepared from a commercial SSP fertilizer (original SSP) by using predetermined milling times of $2.5,5,10,20,40$ and 80 minutes. The milling process was carried out using an orbital mill equipment comprised of a porcelain jar and alumina balls.

\subsection{Characterizations}

$\mathrm{X}$-ray diffraction (XRD) analyzes were performed on a LabX XDR 6000 diffractrometer (Shimadzu, Japan), operating with $\mathrm{Cu}-\mathrm{K} \alpha$ radiation $(\lambda=1.54056 \AA)$, voltage of $30 \mathrm{kV}$ and current of $30 \mathrm{~mA}$. XRD patterns were registered in the angular range $(2 \theta)$ of $5-55^{\circ}$ using a continuous scanning speed of $2^{\circ} \mathrm{min}^{-1}$.

Chemical analyses was done by X-ray fluorescence (XRF) using the lithium tetraborate fusion technique. The 10 most common oxides found in ores were analyzed.

Fourier transform infrared spectroscopy (FT-IR) analyses were performed on a Paragon 1000 spectrometer (PerkinElmer $\left.^{\circledR}\right)$ in the absorbance mode ranging the wavenumber from 4000 to $400 \mathrm{~cm}^{-1}$.

The morphology of the milled SSP samples was observed by field emission gun scanning electron microscopy (FEG-SEM) using a JSM-6701F FEG microscope (JEOL, Japan). The imaging was carried out using an accelerating voltage of $2 \mathrm{kV}$ and secondary electron detector.

Total surface area measurements were done by isothermal nitrogen adsorption on aMicrometritics ASAP 2020 equipment using the 5-points BET (Brunauer-Emmett-Teller) method. ${ }^{14}$

Thermogravimetric analyses (TGA) were performed on a Q500 thermal analyzer (TA Instruments) using synthetic air atmosphere $\left(80 \% \mathrm{~N}_{2}\right.$ and $\left.20 \% \mathrm{O}_{2}\right)$ with a flow of $60 \mathrm{~mL} \mathrm{~min}^{-1}$. Samples were heated up to $1000{ }^{\circ} \mathrm{C}$ using a heating rate of $10^{\circ} \mathrm{C} \mathrm{min}^{-1}$. Differential scanning calorimetry (DSC) analyses were conducted in a Q100 calorimeter (TA Instruments). Samples were placed in an aluminum crucible and heated at a heating rate of $10{ }^{\circ} \mathrm{C} \mathrm{min}-1$ from 25 to $400{ }^{\circ} \mathrm{C}$ under inert nitrogen atmosphere flowing at $40 \mathrm{~mL} \mathrm{m^{-1 }}$.

\subsection{Solubilization tests}

The solubility of the SSP materials was directly tested in deionized water with a resistivity higher than $18.2 \mathrm{M} \Omega \mathrm{cm}$. The solubilization experiments were carried out for 7 days following the model proposed by Tomaszewska and Jarosiewicz ${ }^{15}$ and modified by Pereira ${ }^{16}$. For each experiment, aliquots parts were taken periodically and used to determine the phosphorus concentration released by the SSP sample. In brief, aliquot of $5 \mathrm{~mL}$ was reacted with $2 \mathrm{~mL}$ of ascorbic acid solution $\left(0.4 \mathrm{~mol} \mathrm{~L}^{-1}\right), 0.2 \mathrm{~mL}$ of citric acid $\left(0.03 \mathrm{~mol} \mathrm{~L}^{-1}\right)$ and $2 \mathrm{~mL}$ of a mixed reactant consisting of $25 \mathrm{~mL}$ of a sulfuric acid solution $\left(4.7 \mathrm{~mol} \mathrm{~L}^{-1}\right), 5.5 \mathrm{~mL}$ of ammonium molybdate solution $\left(0.08 \mathrm{~mol} \mathrm{~L}^{-1}\right)$ and $0.6 \mathrm{~mL}$ of antimony and potassium tartrate solution $\left(0.05 \mathrm{~mol} \mathrm{~L}^{-1}\right)$. This mixture was reacted at $50{ }^{\circ} \mathrm{C}$ for 15 minutes to form a phosphoantimonylmolybdenum blue complex (PBC). The PBC concentration was determined by UV-Vis spectrometry at a wavelength of $880 \mathrm{~nm}^{17-18}$ in a Lambda 25 UV-Vis spectrophotometer (Perkin Elmer). Linear function $\left(r^{2}=0.998\right)$ was obtained using several dilutions of phosphorus standard solution in a concentration range from 0.5 to $5 \mathrm{mg} \mathrm{L}^{-1}$.

To evaluate the effectiveness of the milling process on the solubilization of SSP, kinetic parameters were calculated using two models: the first model was developed by Ritger and Peppas ${ }^{19}$, which has been widely used to describe the controlled release of drugs, nutrients, swelling of hydrogels and other systems. ${ }^{20-22}$ The Ritger and Peppas model describes the classical diffusion (referred to as Fickian diffusion) into a thin film where up to $60 \%$ of the released material can be characterized by a constant $k$ multiplied by time raised to a pre-exponential factor $n$, as described by the equation below:

$\frac{M_{t}}{M_{\infty}}=k t^{n}$

Where $\left(\mathrm{M}_{\mathrm{t}}\right)$ is the amount released at time $t,\left(\mathrm{M}_{\infty}\right)$ is the equilibrium amount, i.e. the release of $100 \%$ of the material, (k) is a kinetic constant, and (n) is the pre-exponential factor associated with the type of mechanism. If $n=5$ the diffusion is assumed to be a Fickian diffusion process, and for different $n$ values the diffusion process may be suffering interference of the diffusion matrix. ${ }^{19,23,24}$

The pre exponential factor $(n)$ and kinetic constant $(k)$ are determined by plotting the logarithm of the concentration versus the logarithm of time. Thus the equation takes a linear form where the pre factor $(n)$ and the kinetic constant $(k)$ are the slope coefficient and linear coefficient, respectively, as shown in the equation below:

$\ln \left(\frac{M_{t}}{M_{\infty}}\right)=\ln k+n \ln t$

The other model used in this study was an equation that assumes that the release of nutrient is a second-order reaction where its rate law is given by:

$v=k[A][B]$

Where the velocity $v$ is proportional to a kinetic constant (k) multiplied by the concentrations of $A$ (solvent) and $B$ (solute). Considering that the concentration of solvent $A$ (water) is infinitely greater than the concentration of the solute $B$ (nutrient) its variation over time will be approximately zero or, in other words:

$$
\frac{d[A]}{d t} \approx 0
$$

The concentration of $A$ can be encompassed into the constant $k$ then a law of pseudo first order rate is obtained.

$v=k[A][B]=k^{\prime}[B]$ 
Where the new rate constant $k^{\prime}$ is $k[A]_{0}$. By writing the equation above in a differential form and performing integration between the limits, one can obtain:

$$
\frac{d[B]}{d t}=-k^{\prime}[B]
$$

$\int_{[B]_{0}}^{[B]} \frac{d[B]}{[B]}=-k^{\prime} \int_{0}^{t} d t$

$[B]=[B]_{0} e^{-k^{\prime} t}$

For a typical exponential curve where $t=0$ the amount of nutrient released is also equal to zero, and for an infinite time the amount of nutrient released is equal to $100 \%$.

\section{3-Results and discussion}

Figure 1 shows the XRD pattern of the original SSP fertilizer. The main observed crystalline phases were Gypsum $\left[\mathrm{Ca}\left(\mathrm{SO}_{4}\right) \cdot \mathrm{xH}_{2} \mathrm{O}\right]$ (PDF2 pattern files \#01-089-1445 and \#00006-0226), and a phosphate-rich phase corresponding to di-hydrogen calcium phosphate $\left[\mathrm{Ca}\left(\mathrm{H}_{2} \mathrm{PO}_{4}\right)_{2} \cdot \mathrm{xH}_{2} \mathrm{O}\right](\mathrm{PDF} 2$ pattern file \#00-009-0347). This result confirms the stages envisaged in the chemical reaction for the manufacture of P-fertilizer products earlier described.

Table 1 displays the results of chemical analysis for 10 traces of surface oxides determined by X-ray fluorescence. It is known that the $\mathrm{P}_{2} \mathrm{O}_{5}$ concentration in SSP fertilizers may vary due to the manufacturing process, phosphorus concentration in the pristine rock (used as a raw material) and other factors. According to previous reports ${ }^{9,10,25-27}$, the available $\mathrm{P}$ content values in SSP are in the range from 7\% to $10 \%\left(16 \%\right.$ to $\left.23 \% \mathrm{P}_{2} \mathrm{O}_{5}\right)$, thus the amount of phosphorus obtained in this study is in agreement with the literature and specifications for this fertilizer. It is noteworthy pointing out the high loss on ignition reported in Table 1, which is clearly related to the high amount of hydrated phases occurring in the sample. Other constituents listed in Table 1 were expected as they are contaminant minerals usually found in SSP fertilizers.

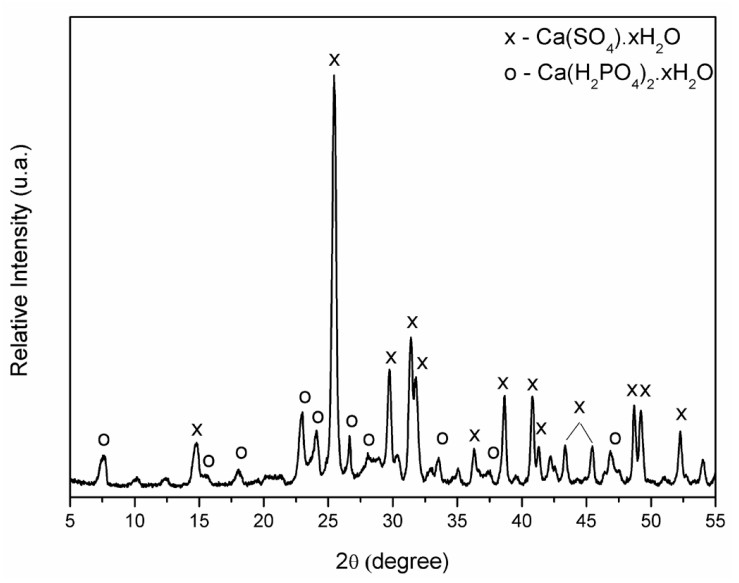

Figure 1. XRD pattern of original (not milled) SSP fertilizer.
The micrographs in Figure 2 reveal that the increase of the milling time provoked a decrease in the SSP particle size. It is observed that the milling process was effective because particle deformation occurred, but one can also notice that small aggregates were formed with increasing milling time. Furthermore, sub-micron particles are visible, which is clearly seen even in the micrograph of the SSP 2.5-min sample. The nitrogen physisorption results presented in Figure 3 show the relative increase of surface area of the SSP powder with increasing milling time, which confirms the features drawn from the SEM micrographs. Earlier studies on grinding mills ${ }^{28-29}$ showed that there is an optimal time for each assembled system (mill and grinding media), i.e., there is a specific time at which the smallest particle size, and consequent largest relative surface area, is reached. After this point, the particle deformation may lead to agglomeration, affecting the total surface area available for adsorption. From Figure 3 it is possible to suggest that the mounted system has not reached its maximum grinding efficiency, as the surface area values of SSP continued increasing with increasing milling time.

Figure 4 shows the FTIR spectrum of the original SSP fertilizer. The infrared spectroscopy was used to confirm the coexistence of two mineral phases, monocalcium phosphate and gypsum, in the majority of phosphate fertilizers. The corresponding vibration bands $\left(\mathrm{OH}^{-}, \mathrm{SO}_{4}^{2-}\right.$ and $\mathrm{PO}_{2}$ chemical groups) have been summarized in Table 2. ${ }^{30-35}$

Thermogravimetric analysis for all samples showed the same profile as that illustrated in Figure 5. The first mass loss between 100 and $250{ }^{\circ} \mathrm{C}^{36-42}$ can be ascribed to the release of water molecules of gypsum which occurrs in two steps as described by Equations 1 and 2:

$$
\begin{aligned}
& \mathrm{CaSO}_{4} \cdot 2 \mathrm{H}_{2} \mathrm{O} \rightarrow \mathrm{CaSO}_{4} \cdot(1 / 2) \mathrm{H}_{2} \mathrm{O}+(3 / 2) \mathrm{H}_{2} \mathrm{O} \\
& \mathrm{CaSO}_{4} \cdot(1 / 2) \mathrm{H}_{2} \mathrm{O} \rightarrow \mathrm{CaSO}_{4}+(1 / 2) \mathrm{H}_{2} \mathrm{O}
\end{aligned}
$$

Calcium phosphate loses water molecules by dehydration reactions at the same temperature range ${ }^{38,43,44}$, also in two stages, as described by Equations 3 and 4:

$$
\begin{aligned}
& \mathrm{Ca}\left(\mathrm{H}_{2} \mathrm{PO}_{4}\right)_{2} \cdot \mathrm{H}_{2} \mathrm{O} \rightarrow \mathrm{Ca}\left(\mathrm{H}_{2} \mathrm{PO}_{4}\right)_{2} \cdot(1 / 2) \mathrm{H}_{2} \mathrm{O}+(1 / 2) \mathrm{H}_{2} \mathrm{O} \\
& \mathrm{Ca}\left(\mathrm{H}_{2} \mathrm{PO}_{4}\right)_{2} \cdot(1 / 2) \mathrm{H}_{2} \mathrm{O} \rightarrow \mathrm{Ca}\left(\mathrm{H}_{2} \mathrm{PO}_{4}\right)_{2}+(1 / 2) \mathrm{H}_{2} \mathrm{O}
\end{aligned}
$$

Table 1. Chemical analysis for the SSP fertilizer.

\begin{tabular}{cc}
\hline Oxides & \% in mass \\
\hline $\mathrm{SiO}_{2}$ & 1.48 \\
$\mathrm{Al}_{2} \mathrm{O}_{3}$ & 0.21 \\
$\mathrm{Fe}_{2} \mathrm{O}_{3}$ & 1.3 \\
$\mathrm{CaO}$ & 28.2 \\
$\mathrm{MgO}$ & 0.67 \\
$\mathrm{TiO}_{2}$ & 0.23 \\
$\mathrm{P}_{2} \mathrm{O}_{5}$ & 23.24 \\
$\mathrm{Na}_{2} \mathrm{O}$ & $<0.1$ \\
$\mathrm{~K}_{2} \mathrm{O}$ & 0.29 \\
$\mathrm{MnO}$ & 0.05 \\
Loss on Ignition & 34.6 \\
\hline
\end{tabular}




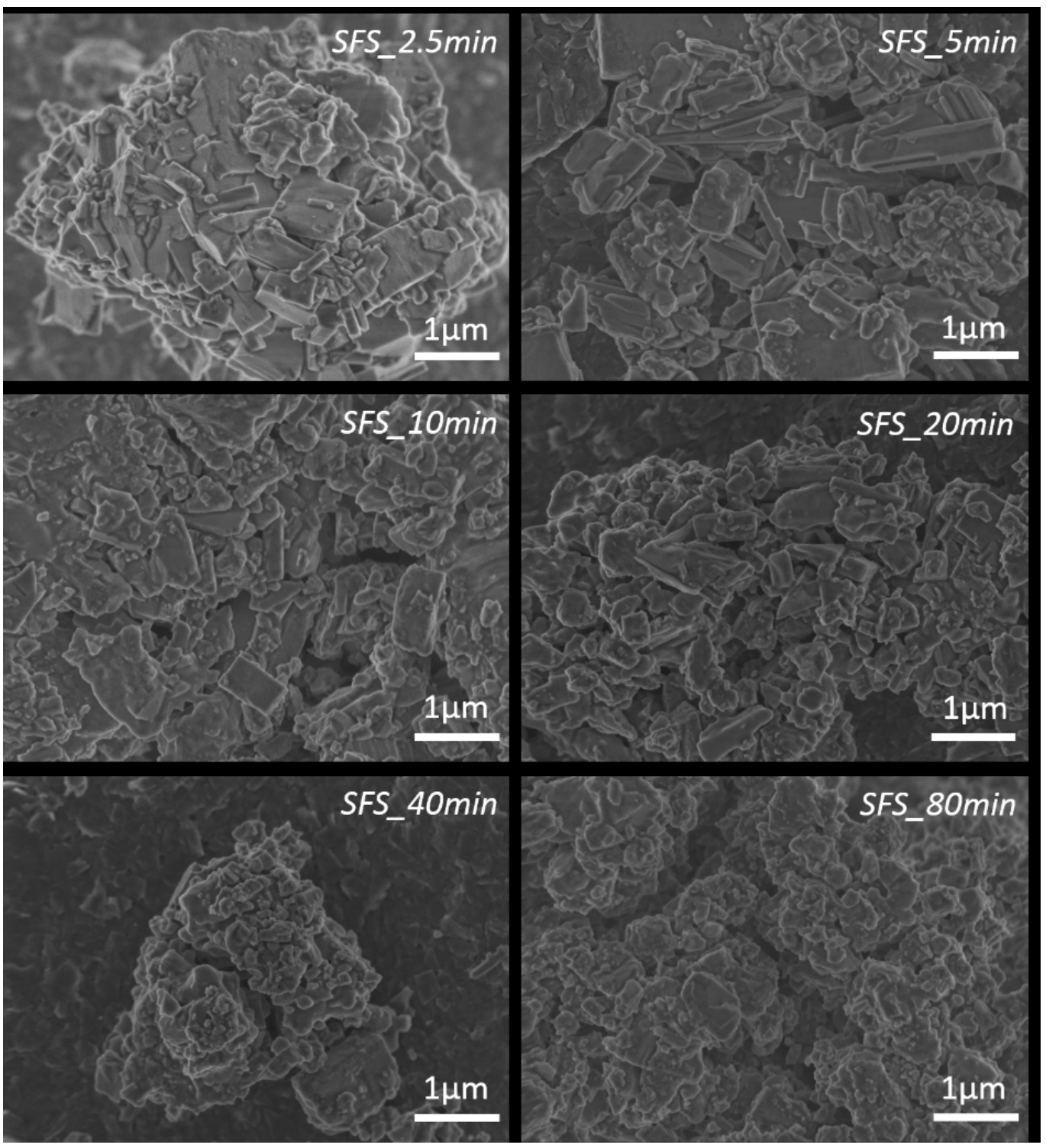

Figure 2. FEG-SEM micrographs of simple superphosphate (SSP) fertilizer milled at different times.

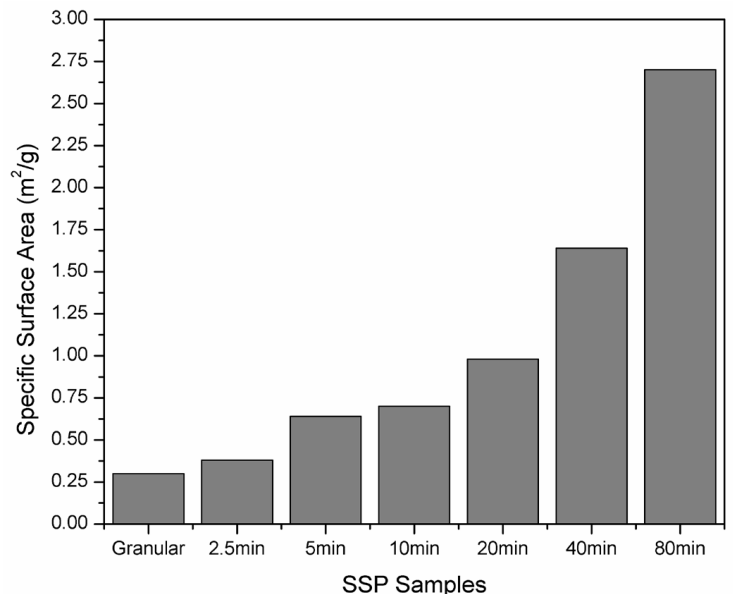

Figure 3. Specific surface are of simple superphosphate (SSP) fertilizer milled at different times.

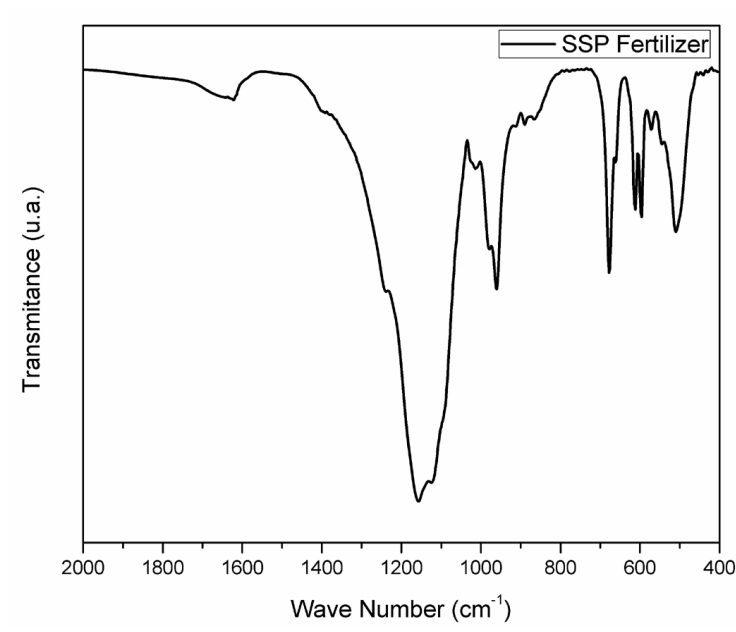

Figure 4. FTIR spectrum of original (not milled) SSP fertilizer. 
As the first gypsum dehydration step corresponds to a mass loss of $75 \%$, one can assume that the DTG peak at $134{ }^{\circ} \mathrm{C}$ corresponds to this water loss of gypsum. On the other hand, the calcium phosphate dehydration is more difficult to be proven, since the phosphate phase is present at smaller quantities in the fertilizer than the gypsum phase. According to refs.[38-44] the complete dehydration for both phases occurs up to $300{ }^{\circ} \mathrm{C}$.

Important thermal events were also observed in the range $550{ }^{\circ} \mathrm{C}-950{ }^{\circ} \mathrm{C}$ as shown in Figure 6 for the original SSP fertilizer and its corresponding milled samples. According to Pyldme et al. (1979) the dihydrogen phosphate undergoes a phase transition at temperatures of approximately $500{ }^{\circ} \mathrm{C}$. In this case, the thermal events observed for the SSP powders cannot be associated with the phase transition of dyhydrogen phosphate since they occurred at higher temperatures $\left(550-950^{\circ} \mathrm{C}\right)$ in the TG/DTG curves. Conversely, gypsum does not undergo any phase transition in the temperature range studied, remaining stable as an anhydrous phase up to $1300{ }^{\circ} \mathrm{C} .{ }^{38,40}$ Thus, the thermal events observed at $550^{\circ} \mathrm{C}-950^{\circ} \mathrm{C}$ must be related to some other intermediary (non-stoichiometric) phases, taking into account that the pristine rocks used in the SSP fertilizer production are typically made up of numerous types of minerals. Nevertheless, it is interesting to note that the increase of milling time shifted the characteristic temperatures of these thermal events toward lower temperature values, from $722^{\circ} \mathrm{C}$ to $674^{\circ} \mathrm{C}$, and from $789^{\circ} \mathrm{C}$ to $762^{\circ} \mathrm{C}$ for the first and second peaks, respectively.

Differential scanning calorimetry (DSC) revealed a similar thermal behavior for all milled SSP samples. A typical DSC trace is shown for SSP_20min in Figure 7. It is possible to note that in the range between $150{ }^{\circ} \mathrm{C}$ and $225^{\circ} \mathrm{C}$ there are only endothermic events. These endothermic events occur

Table 2. IR band assignment for gypsum and monocalcium phosphate.

\begin{tabular}{|c|c|}
\hline Wave number $\left(\mathrm{cm}^{-1}\right)$ & Assignment \\
\hline 1642 & $v_{2}, v_{\mathrm{OH}}$ of $\mathrm{H}_{2} \mathrm{O}$ \\
\hline 1240 & $\delta_{\mathrm{OH}}-$ in plane deformation \\
\hline 1158 & $\mathrm{PO}_{2}$ - asymmetric stretching \\
\hline 1126 & $\mathrm{PO}_{2}$ - symmetric stretching \\
\hline 1010 & $v_{3}-\left(\mathrm{SO}_{4}\right)$ \\
\hline 980 & $\mathrm{P}(\mathrm{OH})_{2}$ - asymmetric stretching \\
\hline 960 & $\mathrm{P}(\mathrm{OH})_{2}$ - asymmetric stretching \\
\hline 912 & $\mathrm{P}(\mathrm{OH})_{2}$ - symmetric stretching \\
\hline 890 & $\mathrm{P}(\mathrm{OH})_{2}$ - symmetric stretching \\
\hline 862 & $\gamma_{\mathrm{OH}}-$ deformation out of plane \\
\hline 678 & $v_{\mathrm{L}}-\mathrm{H}_{2} \mathrm{O}$ vibration mode \\
\hline 662 & $v_{4}-\left(\mathrm{SO}_{4}\right)$ \\
\hline 612 & $v_{4}-\left(\mathrm{SO}_{4}\right)$ \\
\hline 572 & $\mathrm{PO}_{2}$ - bending mode \\
\hline 546 & $\mathrm{PO}_{2}$ - bending mode \\
\hline 508 & $\mathrm{PO}_{2}$ - symmetric deformation in plane \\
\hline 454 & $v_{2}-\left(\mathrm{SO}_{4}\right)$ \\
\hline 442 & $\mathrm{P}(\mathrm{OH})_{2}$ - bending mode \\
\hline
\end{tabular}

within the same temperature range at which mass losses were observed by TGA. Thus, the two peaks in the DSC curve are attributed to the release of structural water molecules of gypsum and calcium phosphate upon heating. ${ }^{39-41}$ Table 3 summarizes the main thermal events observed by TGA and DSC, where these comparisons are clearly stated.

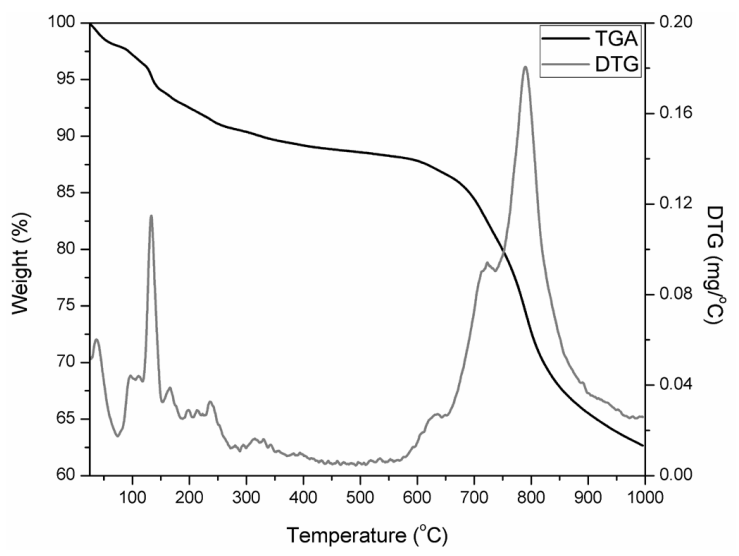

Figure 5. Thermogravimetric (TG) curve and differential thermogravimetric (DTG) curve of original (not milled) SSP fertilizer.

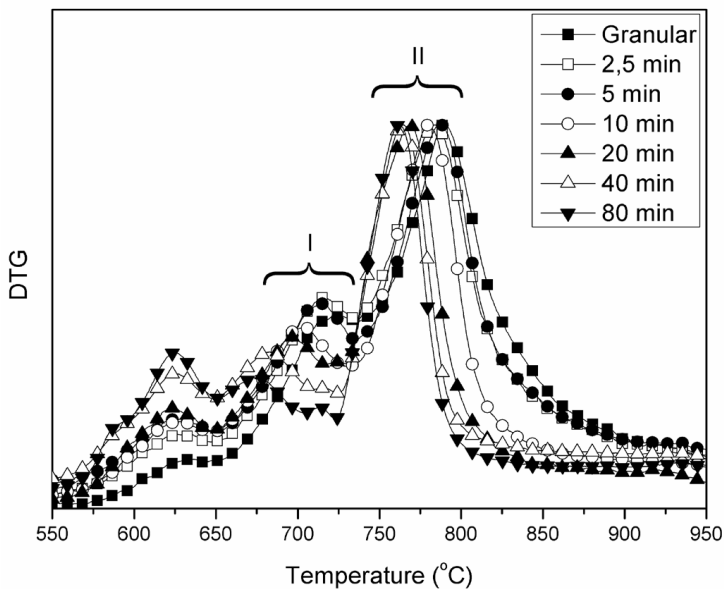

Figure 6. DTG curves of SSP granular and milling samples.

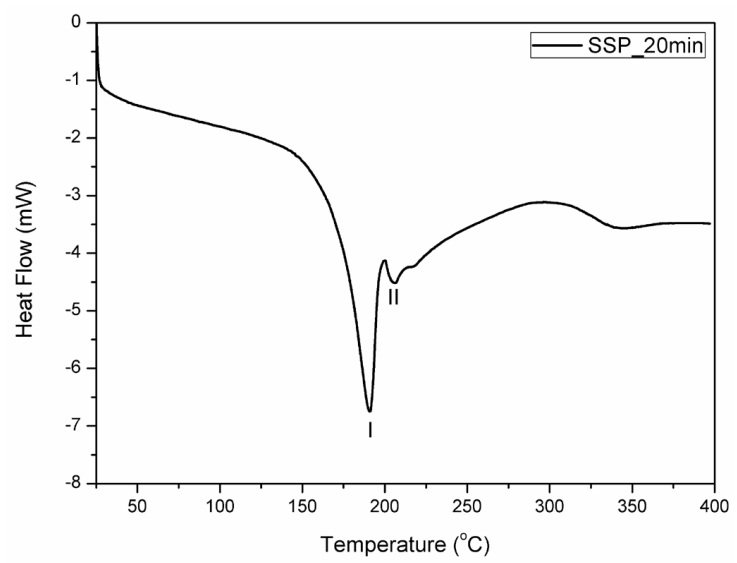

Figure 7. DSC curve of the milled SSP_20 min fertilizer sample. 
Table 3. Summary of TGA and DSC data of SSP fertilizer samples.

\begin{tabular}{lccccc}
\hline \multirow{2}{*}{ Sample } & \multicolumn{3}{c}{ TGA events } & & \multicolumn{2}{c}{ DSC events } \\
\cline { 2 - 3 } \cline { 5 - 6 } & $\mathbf{I}\left({ }^{\circ} \mathbf{C}\right)$ & II $\left({ }^{\circ} \mathbf{C}\right)$ & & I $\left({ }^{\circ} \mathbf{C}\right)$ & -1 \\
\hline SFS_Granular & 722 & 789 & ------ & 201 \\
SFS_2.5 min & 715 & 783 & 194 & 197 \\
SFS_5 min & 714 & 787 & 779 & 191 & 199 \\
SFS_10 min & 703 & 768 & & 191 & 205 \\
SFS_20 min & 695 & 764 & 186 & 195 \\
SFS_40 min & 682 & 762 & 187 & 198 \\
SFS_80 min & 674 & & & \\
\hline
\end{tabular}

Table 4. Kinetic parameters of the phosphate release experiments

\begin{tabular}{|c|c|c|c|c|c|}
\hline \multirow{2}{*}{ Sample } & \multicolumn{3}{|c|}{ Ritger and Peppas Model } & \multicolumn{2}{|c|}{ Pseudo-first-order Model } \\
\hline & $n$ & $k$ & $R^{2}$ & $\boldsymbol{k}$ & $R^{2}$ \\
\hline SFS_Granular & 0.842 & 0.262 & 0.992 & 0.422 & 0.980 \\
\hline SFS_2.5min & 0.930 & 0.278 & 0.972 & 0.490 & 0.985 \\
\hline SFS_5min & 1.196 & 0.177 & 0.959 & 0.414 & 0.895 \\
\hline SFS_10min & 1.191 & 0.212 & 0.995 & 0.531 & 0.939 \\
\hline SFS_20min & 1.273 & 0.189 & 0.994 & 0.390 & 0.965 \\
\hline SFS_40min & 0.888 & 0.275 & 0.979 & 0.537 & 0.981 \\
\hline SFS_80min & 0.682 & 0.335 & 0.979 & 0.590 & 0.993 \\
\hline
\end{tabular}

In order to examine the milling effect on the kinetics of phosphorus release, representative SSP samples were tested in experiments of solubilization in deionized water. It is well known that this type of experiment is highly aggressive because the dihydrogen calcium phosphate is highly soluble in water. On the other hand, the phosphorus release to soil will involve different mechanisms mainly depending on environmental humidity conditions. The results presented in Figure 8 show a relation between milling time and release kinetics: the solubilization of $70 \%$ of the total available phosphate present in the granular SSP was attained after 3 days of immersion in water, whereas the same content of released phosphate was obtained for the SSP_80min sample after 2 days. It is noteworthy mentioning that the milling process was more effective at short milling time, since the SSP_2.5min sample exhibited a significant increase of solubilization and phosphorus release kinetics.

The calculated kinetic parameters are reported in Table 4. It can be seen that the rate constant $(\mathrm{k})$ values calculated by the two models increased as the milling time was increased. But for milling times of 5, 10 and 20 minutes the same trend was not observed. According to the Peppas model, when the value of the factor $(n)$ is greater than 1 , diffusion is considered to be anomalous i.e. the diffusion process suffers some kind of delay. In this case it is possible to suggest that the plaster layers may be acting as a physical barrier, hindering the diffusion of SSP to the aqueous medium. This means that agglomeration of the plaster influences on the solubility of the SSP fertilizer, since the disassembling by milling was effective in increasing its solubilization.

This result should be carefully analyzed, since a rapid release in field may favor the immobilization of phosphate in soil by reacting with iron, aluminum or manganese

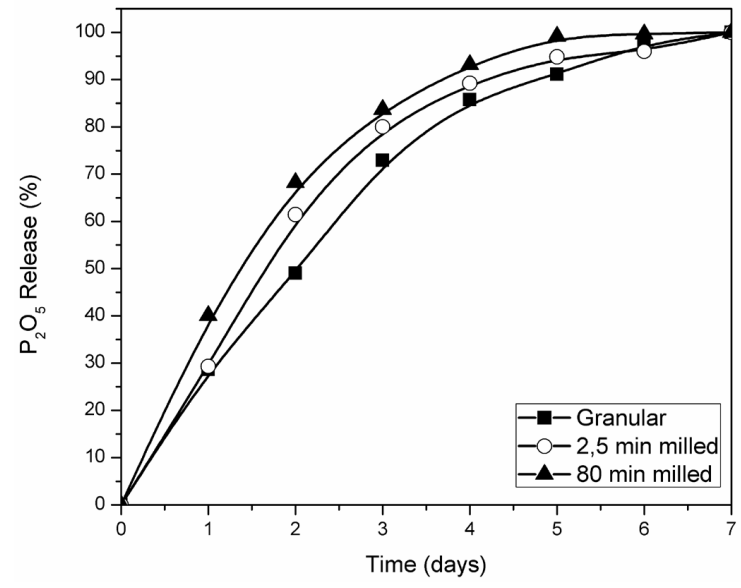

Figure 8. Kinetics of solubilization in aqueous medium for different samples of SSP fertilizers.

species $^{8-9}$. Nevertheless, this result demonstrates that it is possible to consider the orbital milling as a possible route to obtain more efficient P-fertilizers from other low-soluble phosphate fractions.

\section{4 - Conclusions}

The orbital milling process is an effective process to accelerate the solubilization of SSP by reducing the effective particle size of this fertilizer. Despite the regular increase of surface area with increasing milling time, the solubilization kinetics tends to a plateau probably due other effects, such as agglomeration of fertilizer particles. The thermal characterizations were noteworthy, as they revealed that the gypsum phase present in SSP is influenced by milling 
at a highest extent. The orbital milling process could be more effective on more brittle phosphate rocks, which are probably more susceptible to a regular particle size reduction without agglomeration.

\section{6 - References}

1. Marschner H. Mineral nutrition of higher plants. 2nd ed. London: Academic Press; 1995.

2. Isherwood KF. Mineral fertilizer use and the environment. Paris: IFA - International Fertilizer Industry Association; 2000.

3. Cordell D, Drangert JO, White S. The story of phosphorus: Global food security and food for thought. Global Environmental Change. 2009; 19(2):292-305. http://dx.doi.org/10.1016/j. gloenvcha.2008.10.009.

4. Dawson CJ, Hilton J. Fertilizer availability in a resource-limited world: Production and recycling of nitrogen and phosphorus. Food Policy. 2011; 36:S14-S22. http://dx.doi.org/10.1016/j. foodpol.2010.11.012.

5. Franck O. Reactions of superphosphate in the soil. In: ISMA - Technical Meetings; 1947. Landskrona. Sweden. Marbeuf: ISMA; 1947. p. 1-8. Avaliable from: <http://www.fertilizer. org/en/images/Library_Downloads/LE\%2052.pdf>. Access in: 31 Mar. 2015.

6. Ivell DM. Phosphate fertilizer production - from the 1980's to 2011 and beyond. Procedia Engineering. 2012; 46:166-171.

7. Ashley K, Cordell D, Mavinic D. A brief history of phosphorus: from the philosopher's stone to nutrient recovery and reuse. Chemosphere. 2011; 84(6):737-746. http://dx.doi.org/10.1016/j. chemosphere.2011.03.001.

8. Zapata F, Roy RN. Use of phosphate rocks for sustainable agriculture. Roma: Food and Agriculture Organization; 2004. FAO - Fertilizer and Plant Nutrition Bulletin, 13.

9. Nelson LB. Advances in fertilizers. In: Norman AG, editor. Advances in agronomy. New York: Academic Press; 1965. p. 1-84.

10. United Nations Industrial Development Organization (UNIDO), International Fertilizer Development Center (IFDC). Fertilizer manual. 3rd ed. Holland: Kluwer Academic; 1998.

11. Jackson AS. Production of single superphosphate with a TVA cone mixer and belt den. In: Nielsson FT, editor. Manual of fertilizer processing. New York: Marcel Dekker; 1987. p. 125138.

12. Kauwenbergh S J. World phosphate rock reserves and resources. Alabama: IFDC - International Fertilizer Development Center; 2010.

13. Hakam A, Khouloud M, Zeroual Y. Manufacturing of superphosphates SSP \& TSP from down stream phosphates. Procedia Engineering, 2012; 46:154-158. http://dx.doi. org/10.1016/j.proeng.2012.09.459.

14. Atkins PW, Paula J. Físico-química. 8th ed. Rio de Janeiro: LTC - Livros Técnicos e Científicos; 2008.

15. Tomaszewska M, Jarosiewicz A. Use of polysulfone in controlledrelease NPK fertilizer formulations. Journal of Agricultural and Food Chemistry. 2002; 50(16):4634-4639.

16. Pereira EI, Minussi FB, Cruz CC, Berbardi AC, Ribeiro C. Urea-montmorillonite-extruded nanocomposites: A novel showrelease material. Journal of Agricultural and Food Chemistry. 2012; 60:5267-5272.

17. Pai SC, Yang CC, Riley JP. Effects of acidity and molybdate concentration on the kinetics of the formation of the

\section{5 - Acknowledgements}

The authors acknowledge the Brazilian funding agencies CAPES, CNPq, FAPESP, FINEP and Embrapa (Rede Agronano) for their financial support to this research.

phosphoantimonylmolybdenum blue complex. Analytica Chimica Acta. 1990; 229:15-120.

18. Drummond L, Maher W. Determination of phosphorus in aqueous solution via formation of the phosphoantimonylmmolybdenum blue complex Re-examination of optimum conditions for the analysis of phosphate. Analytica Chimica Acta. 1995; 302(1):6974.

19. Ritger PL, Peppas NA. A simple equation for description of solute release I. Fickian and non-fickian release from nonswellable devices in the form of slabs, spheres, cylinders or discs. Journal of Controlled Release. 1987; 5(1):23-36.

20. Aouada FA, Muniz EC, Vaz CM, Mattoso LH. Correlação entre parâmetro da cinética de intumescimento com características estruturais e hidrofílicas de hidrogéis de poliacrilamida e metilcelulose. Quimica Nova. 2009; 32(6):1482-1490. http:// dx.doi.org/10.1590/S0100-40422009000600023.

21. Bortolin A, Aouada FA, Longo E, Mattoso LH. Investigação do processo de absorção de água de hidrogéis de polissacarídeo: efeito da carga iônica, presença de sais, concentrações de monômero e polissacarídeo. Polímeros. 2012; 22(2):311-317.

22. Bortolin A, Aouada FA, Mattoso LH, Ribeiro C. Nanocomposite PAAm/Methyl cellulose/montmorillonite hydrogel: evidence of synergistic effects for the slow release of fertilizers. Journal of Agricultural and Food Chemistry. 2013; 61(31):7431-7439.

23. Ritger PL, Peppas NA. A simple equation for description of solute release II. Fickian and anomalous release from swellable devices. Journal of Controlled Release. 1987; 5(1):37-42.

24. Peppas NA, Shalin J. A simple equation for the description of solute release III. Coupling of diffusion and relaxation. International Journal of Pharmaceutics. 1989; 57(2):169-172.

25. Sinclair AG, Johnstone PD, Watkinson JH, Smith LC, Morton J, Judge A. Comparison of six phosphate rocks and single superphosphate as phosphate fertilizers for clover-based pasture. New Zealand Journal of Agricultural Research. 1998; 41(3):415-420.

26. Loureiro FE, Monte MB, Nascimento M. Agrominerais Fosfato. In: Luz AB, Lins FA, editores. Rochas \& Minerais Industriais - Usos e especificações. 2nd ed. Rio de Janeiro: CETEM-MCT; 2008. p. 141-180.

27. Brasil. Ministério da Agricultura, Pecuária e Abastecimento - MAPA. Instrução Normativa 25/2009. Brasília: Ministério da Agricultura, Pecuária e Abastecimento; 2009. Available from: <http://sistemasweb.agricultura.gov.br/sislegis/action/ detalhaAto.do?method=recuperarTextoAtoTematicaPortal\&c odigoTematica=1229186>. Access in: 31 Mar. 2015.

28. Lim HH, Gilkes RJ, McCormick PG. Beneficiation of rock phosphate fertilisers by mechano-milling. Nutrient Cycling in Agroecosystems. 2003; 67(2):177-186.

29. Tõnsuaadu K, Kaljuvee T, Petkova V, Traksmaa R, Bender V, Kirimae K. Impact of mechanical activation on physical and chemical properties of phosphorite concentrates. International Journal of Mineral Processing. 2011; 100(3):104-109.

30. Takahashi H, Maehara I and Kaneko N. Infrared reflection spectra of gypsum. Spectrochimica Acta. 1983;39A(5):449-455.

31. Nakamoto K. Infrared and raman spectra of inorganic and coordination compounds. 4th ed. New York: John Wiley \& Sons; 1986. 
32. Hug S. In situ fouries transform infrared measurements of sulfate absorption on hematite in aqueous solution. Journal of Colloid and Interface Science. 1997; 188:415-422.

33. Xu J, Gilson DF and Butler IS. FT-Raman and high-pressure FT-infrared spectroscopic investigation of monocalcium phosphate monohydrate. Spectrochimica Acta Part A. 1998; 54(12):1869-1878.

34. Silverstein RM, Webster FX and Kiemle DJ. Spectrometric identification of organic compounds. 7th ed. New York: John Wiley \& Sons; 2005.

35. Anbalagan G, Mukundakumari S, Murugesan KS and Gunasekaran S. Infrared, optical absorption, and EPR spectroscopic studies on natural gypsum. Vibrational Spectroscopy. 2009; 50(2):226230.

36. Badens E, Llewellyn P, Fulconis JM, Jourdan C, Veesler S, Boistelle R, et al. Study of gypsum dehydration by controlled transformation rate thermal analysis (CRTA). Journal of Solid State Chemistry. 1998; 139(1):37-44.

37. Strydom CA and Potgieter JH. Dehydration behaviour of a natural gypsum and a phosphogypsum during milling. Thermochimica Acta. 1999; 332(1):89-96.
38. Ramachandran VS, Paroli RM, Beaudoin JJ and Delgado AH. Handbook of thermal analysis of construction materials. 1st ed. New York: Noyes Publications; William Andrew Publishing; 2002.

39. Wakili KG, Hugi E, Wullscheleger L and Frank T. Gypsum board in fire - modeling and experimental validation. Journal of Fire Sciences. 2007; 25(3):267-282.

40. Kontogeorgos DA, Mandilaras I and Founti M. Scrutinizing gypsum board thermal performance at dehydration temperatures. Journal of Fire Sciences. 2011; 29(2):111-130.

41. Kontogeorgos DA and Founti MA. Gypsum board dehydration kinetics at autogenous water vapor partial pressure. Thermochimica Acta. 2012; 545:141-147.

42. Kontogeorgos DA, Founti MA. Gypsum board reaction kinetics at elevated temperatures. Thermochimica Acta. 2012; 529:6-13.

43. Pyldme M, Tynsuaadu K, Paulik F, Arnold M. Dehydrations of $\mathrm{Ca}\left(\mathrm{H}_{2} \mathrm{PO}_{4}\right)_{2} \cdot \mathrm{H}_{2} \mathrm{O}$ and $\mathrm{Mg}\left(\mathrm{H}_{2} \mathrm{PO}_{4}\right)_{2} \cdot 2 \mathrm{H}_{2} \mathrm{O}$ and their reactions with $\mathrm{KCl}$, examined with simultaneous TG, DTG, DTA, and EGA. Journal of Thermal Analysis. 1979; 17:479-488.

44. Hsu CK. A study on thermal behavior of uncalcined $\mathrm{Ca}\left(\mathrm{H}_{2} \mathrm{PO}_{4}\right)_{2}$. $\mathrm{H}_{2} \mathrm{O}$ and $\mathrm{CaCO}_{3}$ mixtures. Thermochimica Acta. 2002; 392393:157-161. 